\title{
Fabrication of Ultraviolet Photodetectors Based on Fe-Doped ZnO Nanorod Structures
}

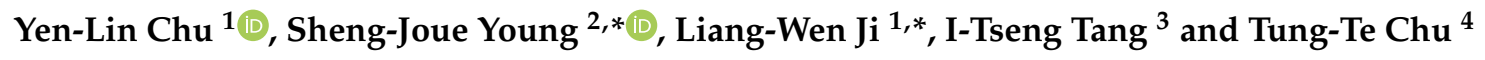 \\ 1 Department of Electro-Optical Engineering \& Institute of Electro-Optical and Materials Science, \\ National Formosa University, Yunlin 632, Taiwan; 10576123@gm.nfu.edu.tw \\ 2 Department of Electronic Engineering, National Formosa University, Yunlin 632, Taiwan \\ 3 Department of Greenergy, National University of Tainan, Tainan 701, Taiwan; tangitseng@gmail.com \\ 4 Department of Mechanical Automation Engineering, Kao Yuan University, Kaohsiung 821, Taiwan; \\ t30039@cc.kyu.edu.tw \\ * Correspondence: shengjoueyoung@gmail.com (S.-J.Y.); lwji@nfu.edu.tw (L.-W.J.); \\ Tel.: +886-5-6315560 (S.-J.Y.); +886-5-6315679 (L.-W.J.); Fax: +886-5-6315643 (S.-J.Y.); +886-5-6329257 (L.-W.J.)
}

Received: 16 June 2020; Accepted: 9 July 2020; Published: 10 July 2020

\begin{abstract}
In this paper, $100 \mathrm{~nm}$-thick zinc oxide $(\mathrm{ZnO})$ films were deposited as a seed layer on Corning glass substrates via a radio frequency (RF) magnetron sputtering technique, and vertical well-aligned Fe-doped $\mathrm{ZnO}$ (FZO) nanorod (NR) arrays were then grown on the seed layer-coated substrates via a low-temperature solution method. FZO NR arrays were annealed at $600{ }^{\circ} \mathrm{C}$ and characterized by using field emission scanning microscopy (FE-SEM) and X-ray diffraction spectrum (XRD) analysis. FZO NRs grew along the preferred (002) orientation with good crystal quality and hexagonal wurtzite structure. The main ultraviolet (UV) peak of $378 \mathrm{~nm}$ exhibited a red-shifted phenomenon with Fe-doping by photoluminescence (PL) emission. Furthermore, FZO photodetectors (PDs) based on metal-semiconductor-metal (MSM) structure were successfully manufactured through a photolithography procedure for UV detection. Results revealed that compared with pure ZnO NRs, FZO NRs exhibited a remarkable photosensitivity for UV PD applications and a fast rise/decay time. The sensitivities of prepared pure $\mathrm{ZnO}$ and FZO PDs were 43.1, and 471.1 for a $3 \mathrm{~V}$ applied bias and $380 \mathrm{~nm}$ UV illumination, respectively.
\end{abstract}

Keywords: zinc oxide; ultraviolet; nanorods; Fe; photodetectors

\section{Introduction}

People's lives have become more comfortable and convenient with the rapid development of the economy, military and industrial technology in the past decade. However, this development has caused several adverse effects, such as greenhouse effect, air pollution and acid rain, which have damaged the ecological balance of Nature. It has also affected the rapidly breaking ozone layer causing a loss of the atmosphere's ultraviolet (UV) filter function. Excessive UV light can directly damage the human body, leading to severe sunburn, skin aging, and skin cancers (e.g., basal cell carcinoma, squamous cell carcinoma, and malignant melanoma) [1-3]. Therefore, high performance UV photodetectors (PDs) have been developed to solve these problems. In recent years, UV PDs have played an important role in different applications which have been extensively explored in the areas of human health, pollution monitoring, flame detection, water sterilization, and missile warning systems [4]. Many metal oxide semiconductors (MOSs) are also employed in UV detection; examples include silicon carbide ( $\mathrm{SiC}$ ), gallium nitride $(\mathrm{GaN})$, titanium dioxide $\left(\mathrm{TiO}_{2}\right)$, and zinc oxide $(\mathrm{ZnO})$ [5-8]. Among them, $\mathrm{ZnO}$ is one of the most explored, partly because of its distinct properties (e.g., non-toxicity, high electron mobility, biocompatibility, and low cost) and potential applications in optoelectronic components. $\mathrm{ZnO}$ is an 
n-type MOS and a group II-VI material, its band gap is about $3.37 \mathrm{eV}$, and it has a large exciton binding energy $(60 \mathrm{meV})$ at room temperature. Moreover, it has a hexagonal structure, and the properties of lattice constants are $\mathrm{a}=3.24-3.26 \AA$ and $\mathrm{c}=5.13-5.43 \AA[9,10] . \mathrm{ZnO}$ has attracted tremendous and wide interest in different fields, such as field-emission displays (FEDs), PDs, gas sensors, and pH sensors [11-14]. Therefore, $\mathrm{ZnO}$ has gradually become a promising material for various applications in modern times.

Based on these properties, $\mathrm{ZnO}$ materials have been extensively employed in UV PDs due to their excellent electronic and photonic properties. ZnO nanostructures are also applied to UV PDs because of their high aspect ratio, high on/off current ratio, rapid response and recovery rate and high photoconductive gain [15]. In previous reports, $\mathrm{ZnO}$ nanostructures were synthesized by using various methods, including pulsed laser deposition (PLD), molecular beam epitaxy (MBE), metal organic chemical vapor deposition (MOCVD), and chemical bath deposition (CBD) methods [16-19]. Among the different growth methods, CBD is an uncomplicated growth method under low temperature conditions and also an inexpensive method. It was employed in the preparation of $\mathrm{ZnO}$ nanostructures in our experiments owing to these outstanding advantages. Until now, ZnO UV PDs have been used to fabricate various structures such as Schottky junctions, P-N junctions and metal-semiconductor-metal (MSM) structures [20-22]. The performance of these devices usually depends on the preparation of $\mathrm{ZnO}$ nanomaterials. Moreover, $\mathrm{ZnO}$ exhibits a large adsorption/desorption behavior for oxygen on the surface, which can reduce the dark current and enhance the responsivity of UV PDs. However, the adsorption/desorption process of oxygen on $\mathrm{ZnO}$ surface usually leads to a long rise/recovery time of $\mathrm{ZnO} U V$ PDs, which limits its practical applications [23]. Iron (Fe) is a good doping candidate to overcome this drawback. It is a donor dopant with good electrical and thermal conductivity, which can improve the responsivity of UV PDs [24].

In this work, we report on the structure morphology, crystal lattice, and optical properties of synthesized Fe-doped ZnO (FZO) nanorod (NR) arrays. These FZO NR arrays are prepared through a simple CBD method with a photolithography procedure. The electrical characteristics of the resulting FZO PD samples were also investigated by several instrumental techniques.

\section{Experimental}

PDs based on FZO NR arrays were fabricated in three stages: (1) in a sputtering system, a ZnO (3-in, 99.9\%) target under the base working pressure in the growth chamber was kept at $5 \times 10^{-6}$ Torr, while the applied radio frequency $(\mathrm{RF})$ power was $30 \mathrm{~W}$, the ratio of $\mathrm{Ar} / \mathrm{O}_{2}$ gas flow was maintained at $12 / 1(\mathrm{sccm})$, and the substrate temperature was $30^{\circ} \mathrm{C}$. The $100 \mathrm{~nm}$-thick $\mathrm{ZnO}$ seed layer prepared in this investigation was firstly deposited on a Corning glass substrate $(1 \mathrm{~cm} \times 1 \mathrm{~cm})$ via a RF magnetron sputtering technique (13.56 MHz) at room temperature for $80 \mathrm{~min}$. (2) The standard photolithography technique was then applied to define a micro-pattern on the substrate by using a shadow mask. A $100 \mathrm{~nm}$-thick silver (Ag) film used as an electrode was evaporated on the $\mathrm{ZnO}$ seed layer using an electron beam evaporation to form the MSM structure. During electrode evaporation, the current and voltage of the electron beam were about $15 \mathrm{~mA}$ and kept above $5 \mathrm{kV}$, respectively. The deposition time was almost $90 \mathrm{~min}$, and temperature was maintained at $110^{\circ} \mathrm{C}$. Subsequently, a lift-off process was used to form a micro-patterned interdigital transducer (IDT) structure. The fingers of the Ag contact electrodes were $10 \mu \mathrm{m}$ long and $3 \mu \mathrm{m}$ wide with $3 \mu \mathrm{m}$ spacing (the active sensing area was $10 \mu \mathrm{m} \times 30 \mu \mathrm{m}$ ). (3) Chemical reagents purchased from Sigma-Aldrich (Merck KGaA, Darmstadt, Germany) were analytical grade and used without further purification in this experiment to fabricate FZO NRs. Aqueous solution of $0.03 \mathrm{M}$ zinc nitrate hexahydrate $\left[\mathrm{Zn}\left(\mathrm{NO}_{3}\right)_{2} \cdot 6 \mathrm{H}_{2} \mathrm{O}, 99.99 \%\right], 0.03 \mathrm{M}$ hexamethylenetetramine $\left(\mathrm{C}_{6} \mathrm{H}_{12} \mathrm{~N}_{4}\right.$, HMTA), and $0.4 \mathrm{mM}$ ferric nitrate nanohydrate $\left[\mathrm{Fe}\left(\mathrm{NO}_{3}\right)_{3} \cdot 9 \mathrm{H}_{2} \mathrm{O}\right.$, $98.4 \%$ ] was mixed with deionized (DI) water and then stirred for $20 \mathrm{~min}$ at $60^{\circ} \mathrm{C}$. When the solution was mixed completely, the $\mathrm{ZnO}$ seed layer grown on a substrate was immersed in a $100 \mathrm{~mL}$ serum bottle containing the mixed aqueous solution for $3 \mathrm{~h}$ at $95^{\circ} \mathrm{C}$ in an oven. After completion of the reaction, the serum bottle was cooled to room temperature, and the sample was washed twice with DI 
water and dried in air for $20 \mathrm{~min}$. DI water from a Milli-Q system $(18.2 \mathrm{M} \Omega \cdot \mathrm{cm})$ was used throughout the experiments. Finally, the samples were annealed in a high vacuum state $\left(\sim 1.5 \times 10^{-5}\right)$ at $600{ }^{\circ} \mathrm{C}$ for 10 min to obtain high-crystallinity nanostructures. Before the UV PDs were manufactured, cleaning the substrate was also an important process because it will affect the growth condition of nanostructures. Thus, all Corning glass substrates were cleaned for $10 \mathrm{~min}$ with acetone, isopropyl alcohol, and DI water. Details of the manufacture of the FZO PDs are shown in Figure 1.

\section{Cleaned the Corning glass substrate}

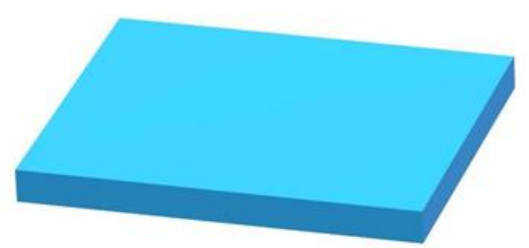

ZnO seed layer deposition
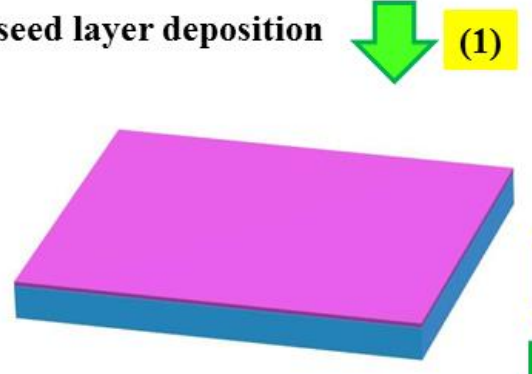

(2)

(3)

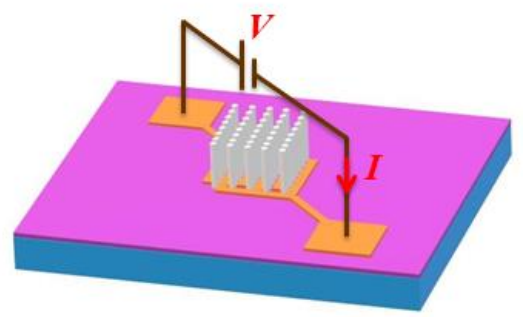

FZO NRs growth

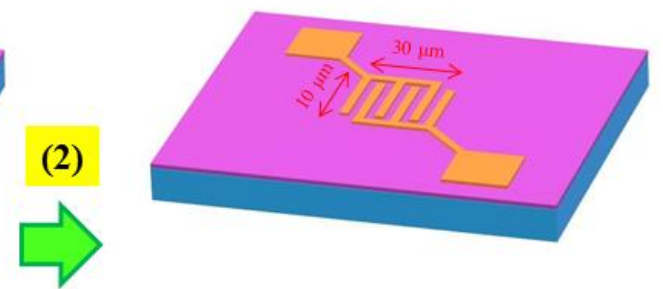

Conductive Ag electrode preparation

Figure 1. Schematic illustration of fabrication steps of FZO NR-based MSM UV PDs.

The surface morphology and lattice properties of the synthesized ZnO NRs with Fe content were observed by using a field emission scanning electron microscope (FE-SEM, JSM-6700F, JEOL, Tokyo, Japan) operated at $15 \mathrm{kV}$ and a high-resolution transmission electron microscope (HR-TEM, JEOL JEM-2100F CS-STEM, Tokyo, Japan) to explore the properties of the material and the device. Fe contents in the samples were checked by using an energy dispersive X-ray (EDX) spectrometer. An X-ray diffractometer (XRD, MO3XHF22 MAC-Science, Kanagawa, Japan) with Cu K $\alpha$ radiation $(\lambda=0.15418 \mathrm{~nm})$ was used to explore crystallographic and structural characteristics of the as-grown pure $\mathrm{ZnO}$ and FZO NR arrays. Optical properties of the as-prepared samples were investigated by using a photoluminescence spectrometer (PL, Labram HR, Horiba, Ltd., Horiba, Ltd., Kyoto, Japan) with a He-Cd laser ( $325 \mathrm{~nm}, 5 \mathrm{~mW}$ ) as the excitation light source. An HP-4156C semiconductor parameter analyzer (Agilent Technologies Inc, Santa Clara, CA, USA.) was then employed to measure current-time $(I-T)$, current-voltage $(I-V)$, photocurrent, and dark current characteristics of fabricated pure $\mathrm{ZnO}$ and FZO PD samples. The photoresponsivity $(A / W)$ measurements were also conducted using a TRIAX 180 monochromator system (Horiba, Ltd., Kyoto, Japan) with a $300 \mathrm{~W}$ xenon arc lamp light source and a 2410 semiconductor system (Keithley, Agilent Technologies Inc, Santa Clara, CA, USA.) at room temperature.

\section{Results and Discussion}

The surface morphology and structural dimensions of samples were characterized by using FE-SEM. Figure 2 shows that NR arrays grew on the substrate from the solutions containing equi-molarity concentrations of $(0.03 \mathrm{M}) \mathrm{Zn}\left(\mathrm{NO}_{3}\right)_{2} \cdot 6 \mathrm{H}_{2} \mathrm{O}$ and $(0.03 \mathrm{M})$ HMTA in the absence of $\mathrm{Fe}^{3+}$ ions and with Fe-doping. During the growth of the nanostructure, $\mathrm{ZnO}$ film was used as seed layer to assist the 
growth of NR arrays. $\mathrm{Zn}^{2+}$ and $\mathrm{OH}^{-}$ions provided by hydration of $\mathrm{Zn}\left(\mathrm{NO}_{3}\right)_{2} \cdot 6 \mathrm{H}_{2} \mathrm{O}$ and HMTA likely reacted with $\mathrm{OH}^{-}$and formed soluble $\mathrm{Zn}(\mathrm{OH})_{2}$ complexes, which are the growth units of $\mathrm{ZnO}$ structures. Finally, a $\mathrm{ZnO}$ nanostructure was generated by the decomposition of $\mathrm{Zn}(\mathrm{OH})_{2}$. Moreover, $\mathrm{Fe}^{3+}$ ions were mostly in the form of Fe precursors and Fe complexes. Figure 2a-d show the top view and cross-section of pure $\mathrm{ZnO}$ and FZO NRs. Growth of the FZO NRs proceeded by the following chemical reaction $[25,26]$ :

$$
\begin{gathered}
\mathrm{Zn}\left(\mathrm{NO}_{3}\right)_{2} \cdot 6 \mathrm{H}_{2} \mathrm{O} \rightarrow \mathrm{Zn}^{2+}+2 \mathrm{NO}_{3}{ }^{-}+6 \mathrm{H}_{2} \mathrm{O} \\
\mathrm{Fe}\left(\mathrm{NO}_{3}\right)_{3} \cdot 9 \mathrm{H}_{2} \mathrm{O} \rightarrow \mathrm{Fe}^{3+}+3 \mathrm{NO}_{3}{ }^{-}+9 \mathrm{H}_{2} \mathrm{O} \\
\mathrm{C}_{6} \mathrm{H}_{12} \mathrm{~N}_{4}+6 \mathrm{H}_{2} \mathrm{O} \rightarrow 6 \mathrm{HCOH}+4 \mathrm{NH}_{3} \\
\mathrm{NH}_{3}+\mathrm{H}_{2} \mathrm{O} \rightarrow \mathrm{NH}_{4}{ }^{+}+\mathrm{OH}^{-} \\
\mathrm{Zn}^{2+}+2 \mathrm{OH}^{-} \rightarrow \mathrm{Zn}(\mathrm{OH})_{2} \\
\mathrm{Fe}^{3+}+3 \mathrm{OH}^{-} \rightarrow \mathrm{Fe}(\mathrm{OH})_{3} \\
\mathrm{Zn}^{2+}+\mathrm{Fe}^{3+}+5 \mathrm{OH}^{-} \rightarrow \mathrm{Zn}(\mathrm{OH})_{2}+\mathrm{Fe}(\mathrm{OH})_{3} \\
\mathrm{Zn}(\mathrm{OH})_{2} \stackrel{\leftrightarrow}{\leftrightarrow} \mathrm{ZnO}+\mathrm{H}_{2} \mathrm{O} \\
2 \mathrm{Fe}(\mathrm{OH})_{3} \stackrel{\Delta}{\leftrightarrow} \mathrm{Fe}_{2} \mathrm{O}_{3}+3 \mathrm{H}_{2} \mathrm{O} \\
\mathrm{Zn}(\mathrm{OH}) 2+2 \mathrm{Fe}(\mathrm{OH})_{3} \stackrel{\leftrightarrow}{\leftrightarrow} \mathrm{ZnO}+\mathrm{Fe}_{2} \mathrm{O}_{3}+4 \mathrm{H}_{2} \mathrm{O}
\end{gathered}
$$

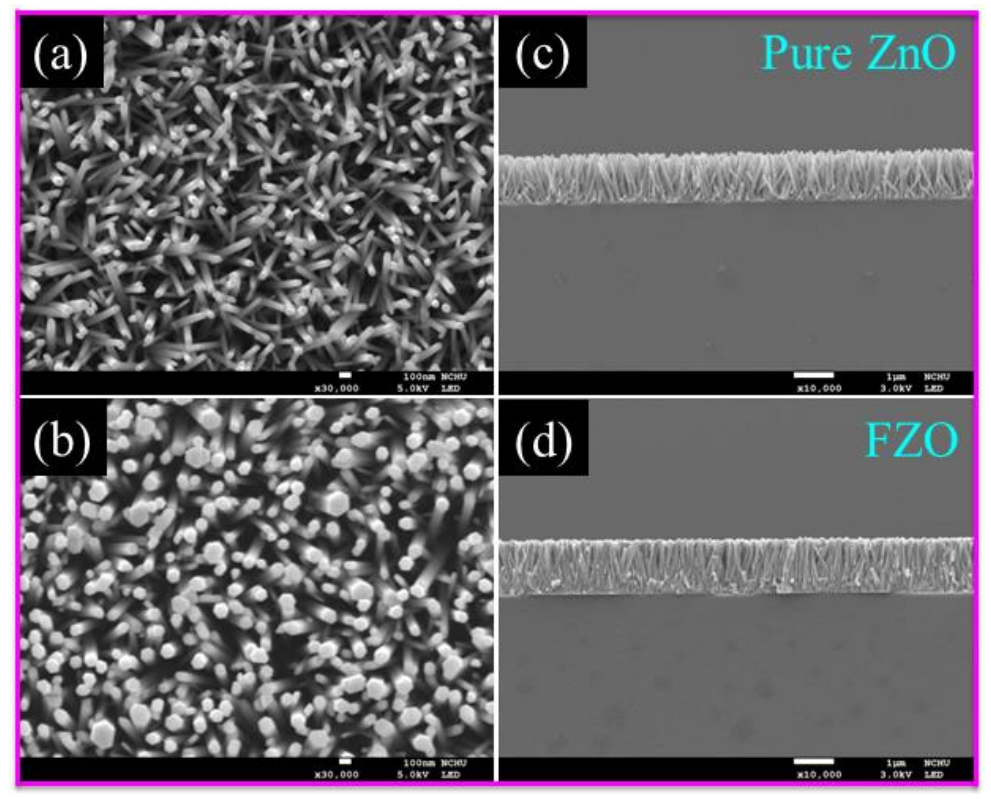

Figure 2. FE-SEM $(\mathbf{a}, \mathbf{b})$ top view and $(\mathbf{c}, \mathbf{d})$ cross-sectional micrographs of $\mathrm{ZnO}$ NR arrays prepared via the aqueous solution method with and without Fe content.

The figure shows the formation of highly oriented hexagonal-shaped NRs nearly vertical to the substrate surface. In pure ZnO FE-SEM, top view and cross-section images exhibit that the diameter and length of the NRs were about $97 \mathrm{~nm}$ and $1.3 \mu \mathrm{m}$, respectively. After Fe-doping, the diameter and length of NRs were increased slightly. The results of this paper are similar to those of a previous report by Liu et al. and Sahai et al $[26,27]$.

XRD measurements were carried out to determine the crystallinity properties of pure $\mathrm{ZnO}$ and FZO NRs shown in Figure 3. The XRD diffraction peaks of all synthesized samples clearly reflect a 
wurtzite structure with typical hexagonal crystals (JCPDS Card No. 36-1451). The XRD pattern of pure $\mathrm{ZnO}$ reveals three peaks at $2 \theta=34.54^{\circ}, 47.69^{\circ}$, and $62.94^{\circ}$, which corresponded to the (002), (102), and (103) planes. The XRD pattern of the Fe-doped sample is similar to that of pure $\mathrm{ZnO}$ structure. No reflection peaks of $\mathrm{Fe}_{2} \mathrm{O}_{3}$ (JCPDS Card No. 33-0664) or $\mathrm{Fe}_{3} \mathrm{O}_{4}$ (JCPDS Card No. 85-1436) can be seen in the diffraction patterns. The absence of impurity peaks suggests that the samples are highly crystalline and have good crystal quality [28]. A strong (002) preferential orientation is also observed in pure $\mathrm{ZnO}$ and FZO structure. This finding implies that all samples are single crystalline and vertically grown on the substrate. Moreover, based on Bragg's Law formula, the shift position in the diffraction angles at (002) peak is derived from the decrease of d-spacing [29]:

$$
\mathrm{n} \lambda=2 \mathrm{~d} \sin \theta
$$

where $n, \lambda, \theta$, and $d$ are the order of diffraction, wavelength of the x-rays, angle of diffraction, and distance between planes, respectively. The inset of Figure 3 shows that the location of the (002) diffraction peak slightly shifts toward higher diffraction angles, which indicates the change in d-spacing. This result implies that the ionic radii value of $\mathrm{Fe}^{3+}(0.068 \mathrm{~nm})$ is smaller than that of $\mathrm{Zn}^{2+}$ ion $(0.074 \mathrm{~nm})$, and Fe atoms may substitute $\mathrm{Zn}^{2+}$ sites or incorporate interstitially in the $\mathrm{ZnO}$ structure [30,31].

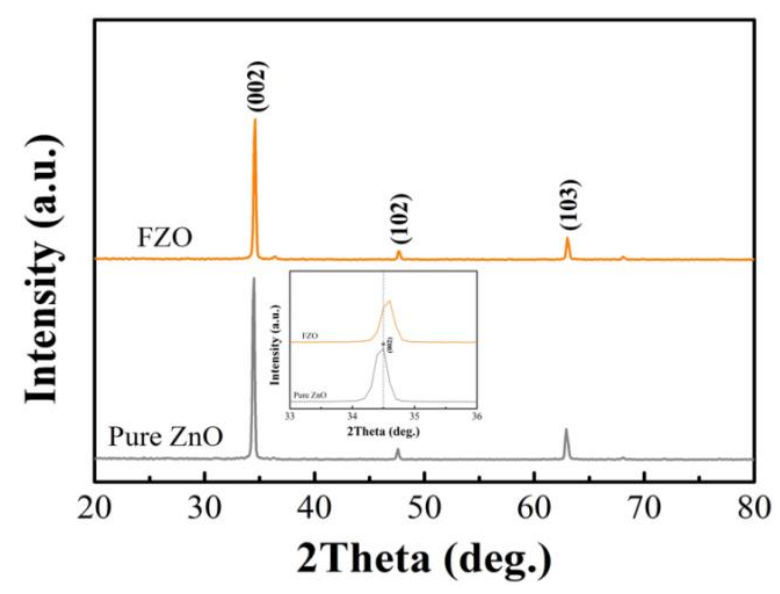

Figure 3. Comparative XRD analysis on pure ZnO and FZO NRs synthesized using the CBD method. [Figure inset shows that the (002) peak of FZO NRs has an angle shift of $0.16^{\circ}$ toward a higher angle compared with pure $\mathrm{ZnO} \mathrm{NRs}]$.

The optical properties of pure $\mathrm{ZnO}$ and FZO PDs were investigated via room temperature PL measurement. PL spectroscopy is a sensitive, non-destructive technique and is appropriate for identifying intrinsic and extrinsic defects in materials. Figure 4 shows the normalized PL spectra of pure $\mathrm{ZnO}$ and FZO NRs with a He-Cd laser $(325 \mathrm{~nm}, 5 \mathrm{~mW})$ as the excitation-light source. According to a previous report [32], the PL spectrum of pure $\mathrm{ZnO}$ structure consists of two major peak regions: (1) a sharp peak located at UV emission (near-band emission, NBE) and (2) a broad peak in the visible green emission (deep-level emission, DLE). The appearance of UV emission and visible green emission reveals the presence of native, intrinsic defects in $\mathrm{ZnO}$, such as interstitial zinc $\left(\mathrm{Zn}_{\mathrm{i}}\right)$, zinc vacancy $\left(V_{Z n}\right)$, oxygen vacancy $\left(V_{O}\right)$, interstitial oxygen $\left(\mathrm{O}_{\mathrm{i}}\right)$, zinc antisite, and oxygen antisite. PL spectra of FZO NRs in the wavelength range of 300-700 nm are also observed. All spectra on the strong UV peak vary from $379 \mathrm{~nm}$ to $385 \mathrm{~nm}$ for 0 to $0.4 \mathrm{mM}$ Fe-doping. Compared with the PL result of pure $\mathrm{ZnO}$, it was revealed that it was red-shifted in the UV emission region and the visible green emission of the FZO NRs decreased slightly. These phenomena can be explained as follows: (1) band gap varied due to sp-d exchange interactions in the $\mathrm{ZnO}$ matrix; and (2) Fe-doping may supply competitive pathways for recombination, resulting in quenching of the visible green emission. These phenomena are similar to the result reported earlier for Fe-doping in $\mathrm{ZnO}$ structure [33-35]. 


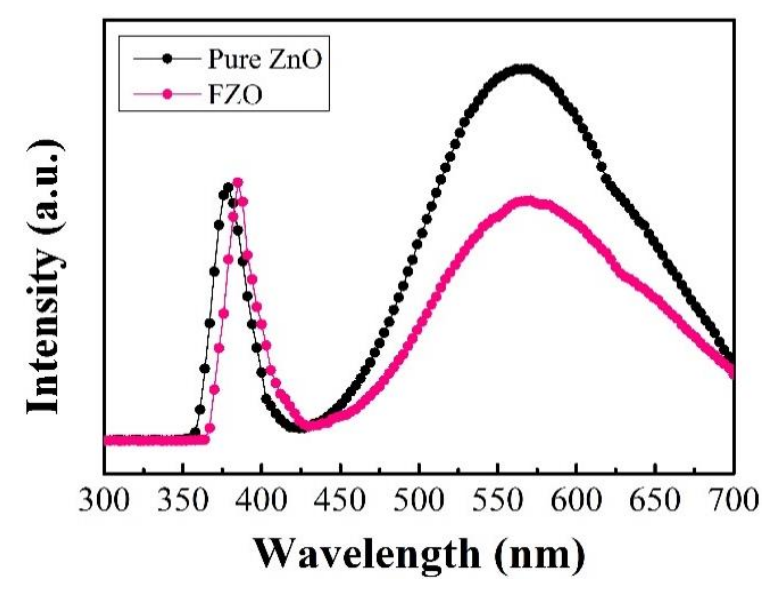

Figure 4. PL spectra of pure ZnO NRs and FZO NRs at $5 \mathrm{~W}$ with an excitation source of $325 \mathrm{~nm}$; UV emission of FZO NRs has a red-shifted of $6 \mathrm{~nm}$ compared with that of pure ZnO NRs.

TEM, HR-TEM, SAED, and EDX images of the synthesised FZO NRs were observed in Figure 5. Figure 5a shows a low-magnification TEM image of the single FZO NR structure. Figure $5 \mathrm{~b}$ reveals that the d-spacing between adjacent lattice planes was $0.258 \mathrm{~nm}$, which appeared to be oriented in the $c$-axis direction. The inset of Figure $5 b$ exhibits that the FZO NR has a single crystalline structure.

Meanwhile, Figure $5 \mathrm{~d}-\mathrm{g}$ show the elemental mapping images of the $\mathrm{ZnO}$ NRs with F content. It can be found that $\mathrm{Zn}$ (red), $\mathrm{O}$ (yellow), and Fe (cyan) elements are uniformly distributed in the FZO NR structure, this means Fe ions may enter into ZnO lattice. The EDX image taken from top view in Figure 2 consists of $\mathrm{Zn}, \mathrm{O}$, and Fe peaks and confirms the presence of Fe content about $0.51 \mathrm{at} \%$ into the sample, as shown in Figure $5 \mathrm{~h}$.

Figure 6 shows $I-T$ and $I-V$ characteristics of pure $\mathrm{ZnO}$ and FZO structure-based UV PDs. Figure $6 \mathrm{a}, \mathrm{b}$ depict the photocurrent rise and decay obtained by turning the continuous UV illumination on and off with a $3 \mathrm{~V}$ applied bias. In this work, rise times $\left(\mathrm{r}_{1}, \mathrm{r}_{2}\right)$ reveal the time for photocurrent rise to $50 \%$ and $90 \%$ of the peak value, respectively; and decay times $\left(d_{1}, d_{2}\right)$ indicate the time for the photocurrent decays to $50 \%$ and $10 \%$ of the peak value, respectively. In the coefficients of all samples, the transient's response during turn-on and turn-off process can be intently fitted via exponential curves, as indicated in the following equations [36]:

$$
\begin{aligned}
& \text { Turn - on : } I(t)=I_{0}(t)\left[1-\exp \left(\frac{-t}{\tau_{r}}\right)^{\beta}\right] \\
& \text { Turn - off : } I(t)=I_{0}(t)\left[\exp \left(\frac{-t}{\tau_{d}}\right)^{\beta}\right]
\end{aligned}
$$

where $\mathrm{I}_{0}(\mathrm{t}), \mathrm{t}, \beta$, and $\tau$ are the transient current, time after turn-on/turn-off, decay exponent, and time constant, respectively. The fitted exponential curves indicate that $\beta$ is about $\sim 1$. Compared with pure ZnO NRs, the rise times $\left(r_{1}, r_{2}\right)$ of FZO were 2 and $46 \mathrm{~s}$, respectively; and the decay times $\left(\mathrm{d}_{1}, \mathrm{~d}_{2}\right)$ were 2 and $37 \mathrm{~s}$, respectively. As a result, both times of FZO PD samples are faster than those of pure $\mathrm{ZnO}$ PD samples. The measurement of continuity is shown in the insets of Figure $6 a, b$. They show that the reproducibility of pure $\mathrm{ZnO}$ and FZO samples is stable (the cyan block area is under $380 \mathrm{~nm}$ UV irradiation). The carrier relaxation phenomenon can be divided into two electronic processes: first, electron loss due to recombination at the deep defect states; second, electron trapping by the surface states [36,37]. I- $V$ curves for the UV sensing of $\mathrm{ZnO}$ PDs with and without Fe content are shown in Figure $6 \mathrm{c}, \mathrm{d}$. The result displays all measured PDs from $-5 \mathrm{~V}$ to $+5 \mathrm{~V}$ bias voltages. 

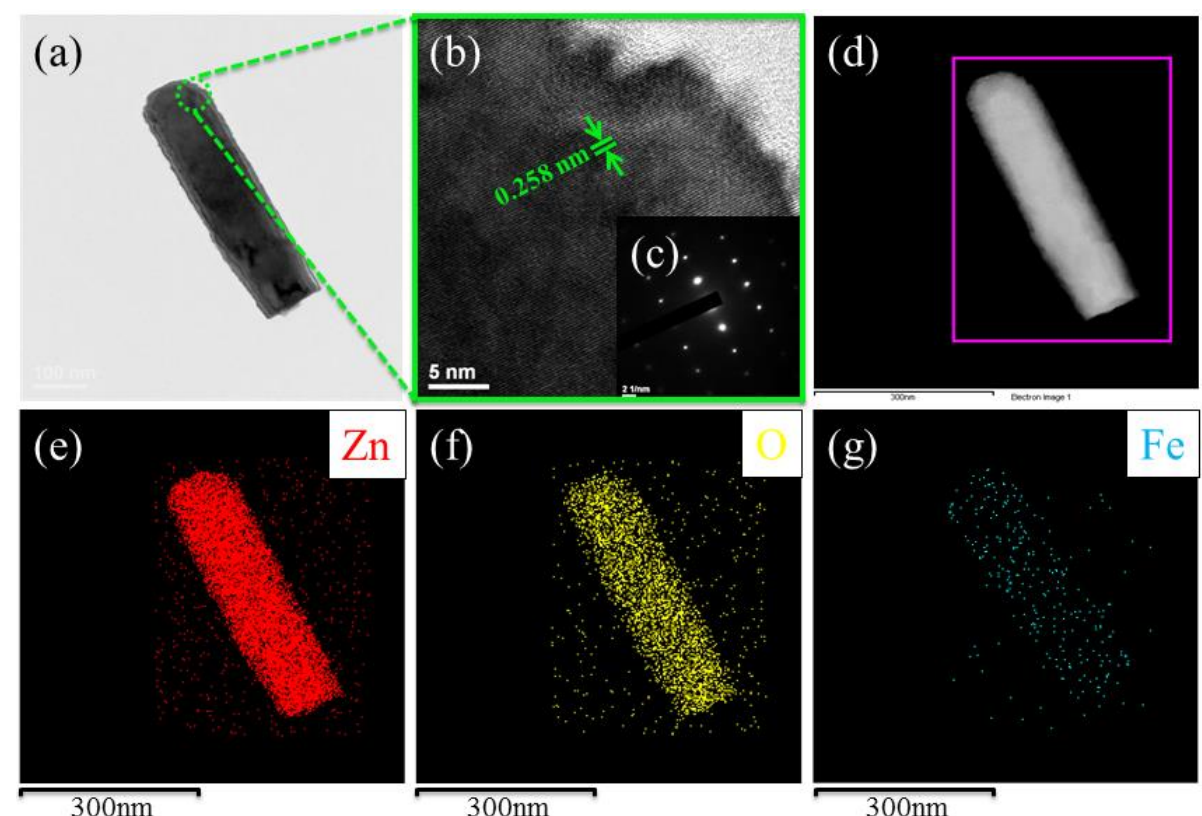

$300 \mathrm{~nm}$

$300 \mathrm{~nm}$

$300 \mathrm{~nm}$

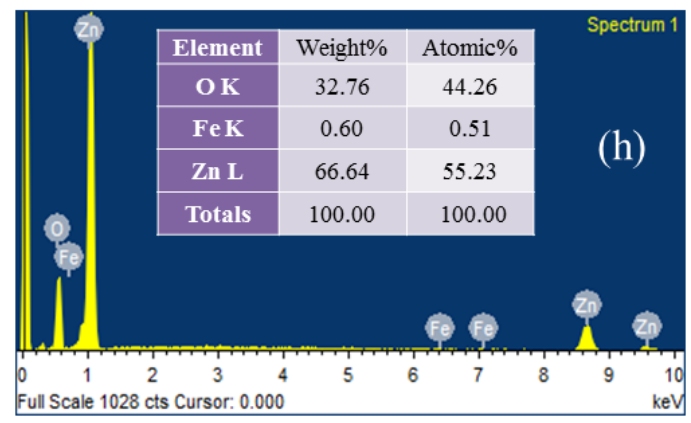

Figure 5. (a) Low-magnification BF TEM micrograph of FZO NR sample grown on substrate. (b) HR-TEM image of tip of the FZO NRs, where inset (c) corresponds to the SAED pattern of FZO NRs. (d-g) TEM elemental mapping images of as-prepared FZO NR structure for the selected region, displaying the existence of $\mathrm{Zn}$ (red), $\mathrm{O}$ (yellow), and Fe (cyan). (h) EDX spectra of as-synthesized FZO NR arrays.

These PD devices are prepared as MSM structures that belong to the back-to-back Schottky junction. This designed structure is similar to that reported earlier for the FZO structure [38]. As a result, with a $3 \mathrm{~V}$ applied bias and $380 \mathrm{~nm}$ UV illumination, the sensitivities $\left(\mathrm{I}_{\mathrm{ph}} / \mathrm{I}_{\mathrm{dark}}\right)$ of fabricated pure $\mathrm{ZnO}$ and FZO PDs were 43.1, and 471.1, respectively. Thus, Fe-doping can reduce the dark current and enhance the electrical properties of PDs, as shown in Table 1. 

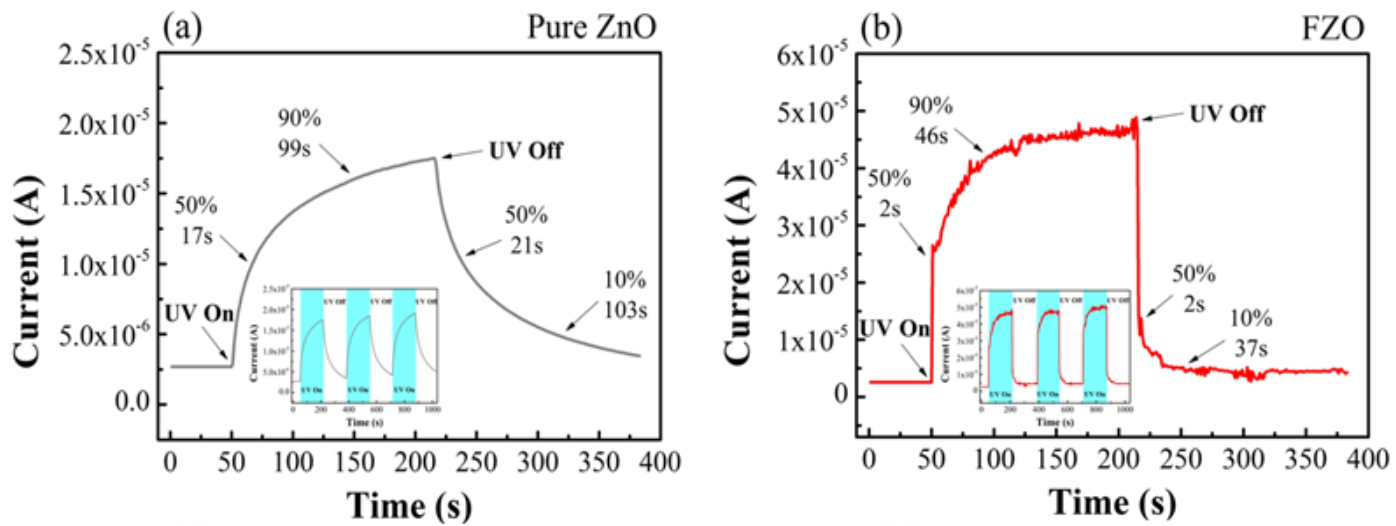

(c)

Pure $\mathrm{ZnO}$
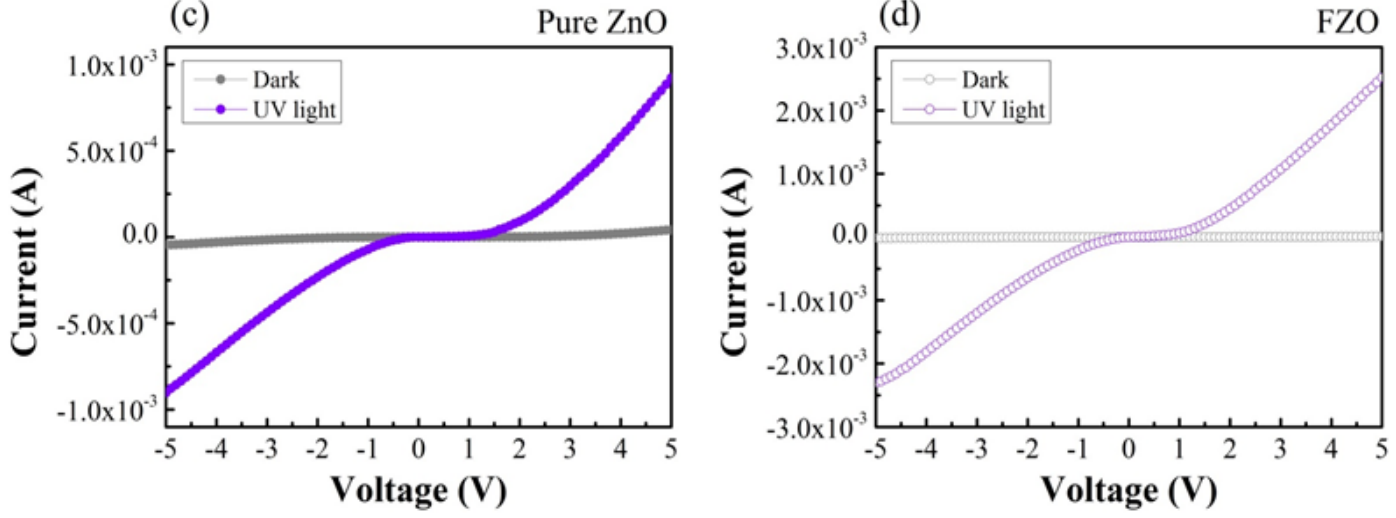

Figure 6. (a,b) $I-T$ responses of photocurrent from pure $\mathrm{ZnO}$ and FZO NR PDs to UV light at 3 $\mathrm{V}$ applied bias. (c,d) $I-V$ characteristics of fabricated ZnO MSM PDs with and without Fe content measured in the dark and $380 \mathrm{~nm}$ UV light environment.

Table 1. The results exhibited the parameters of the prepared PD samples with and without Fe content at $3 \mathrm{~V}$.

\begin{tabular}{cccccccc}
\hline $\begin{array}{c}\text { PD } \\
\text { Samples }\end{array}$ & $\begin{array}{c}\tau_{\mathrm{r} 1} \\
(\mathbf{s})\end{array}$ & $\begin{array}{c}\tau_{\mathrm{r} 2} \\
(\mathbf{s})\end{array}$ & $\begin{array}{c}\boldsymbol{\tau}_{\mathrm{d} 1} \\
(\mathbf{s})\end{array}$ & $\begin{array}{c}\boldsymbol{\tau}_{\mathrm{d} 2} \\
(\mathbf{s})\end{array}$ & $\begin{array}{c}\mathbf{I}_{\text {dark }} \\
(\mathbf{A})\end{array}$ & $\begin{array}{c}\mathbf{I}_{\text {photo }} \\
(\mathbf{A})\end{array}$ & Sensitivity \\
\hline Pure ZnO & 17 & 99 & 21 & 103 & $6.89 \times 10^{-6}$ & $2.97 \times 10^{-4}$ & 43.1 \\
FZO & 2 & 46 & 2 & 37 & $2.25 \times 10^{-6}$ & $1.06 \times 10^{-3}$ & 471.1 \\
\hline
\end{tabular}

The spectral responsivities of pure $\mathrm{ZnO}$ and FZO PDs with an applied bias of $3 \mathrm{~V}$ and under $380 \mathrm{~nm}$ illumination are shown in Figure 7. Responsivities are nearly constant in the UV region (300 to $375 \mathrm{~nm}$ ). Here, we define UV-to-visible rejection ratio as the responsivity measured at $370 \mathrm{~nm}$ divided by the responsivity at $550 \mathrm{~nm}$. The UV-to-visible rejection ratios for pure ZnO and FZO MSM PDs were 96.03 and 1273.61, respectively. These results show that the responsivities for the prepared pure $\mathrm{ZnO}$ and FZO PDs were 0.298 and $0.758 \mathrm{~A} / \mathrm{W}$, respectively. A calibrated measurement of the monochromated xenon arc lamp irradiance was about $30 \mathrm{~W} / \mathrm{m}^{2}$. The responsivity $(\mathrm{R})$ of a PD is defined as the following equation [39]:

$$
\mathrm{R}=\mathrm{I}_{\mathrm{ph}} / \mathrm{P}_{\text {inc }}
$$

where $\mathrm{I}_{\mathrm{ph}}$ and $\mathrm{P}_{\text {inc }}$ are the photocurrent and incident optical power, respectively. As a donor, $\mathrm{Fe}^{3+}$ ion usually provides a pair of electrons in the conduction band, thus improving the photoconductivity [40]. As a result, FZO PDs have better performance than pure ZnO PDs. The large UV-to-visible rejection ratio of FZO samples also implies that the PD with Fe content is potentially useful for practical applications. 


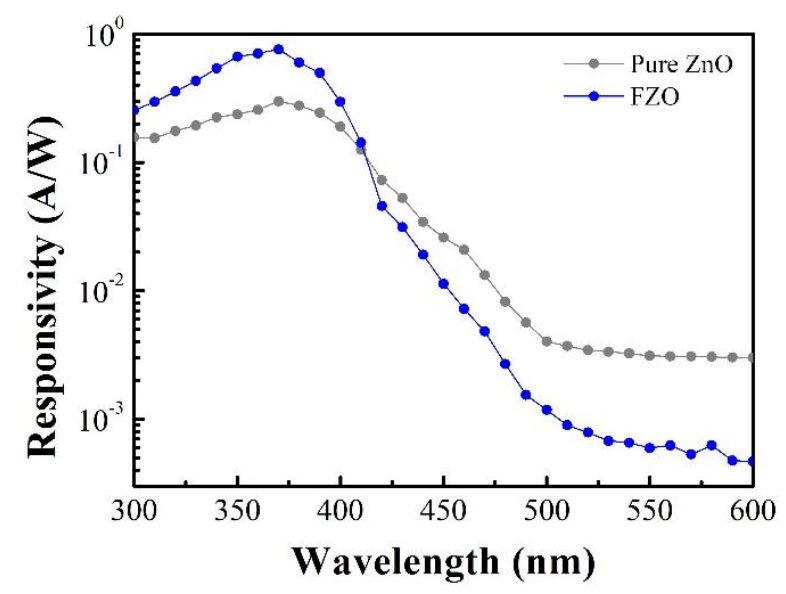

Figure 7. Measured spectral responsivities of MSM PDs based on pure ZnO and FZO NRs with an applied voltage of $3 \mathrm{~V}$ at room temperature.

Figure 8 shows a model mechanism for charge transport in FZO NR-based MSM PDs. Oxygen $\left(\mathrm{O}_{2}\right)$ molecules are adsorbed onto the surface of $\mathrm{ZnO}$ material as negatively charged ions via capturing free electrons from the n-type $\mathrm{ZnO}$ structure, which can produce a low conductivity depletion layer near the surface of pure $\mathrm{ZnO}$ NRs in dark conditions $\left[\mathrm{O}_{2}\right.$ (gas) $+\mathrm{e}^{-} \rightarrow \mathrm{O}_{2}{ }^{-}$(adsorption)]. However, under UV irradiation, UV light ( $\mathrm{hv}>\mathrm{Eg}$ ) photogenerates electron-hole pairs and discharges the adsorbed oxygen $\left(\mathrm{O}_{2}{ }^{-}\right)$ions through surface electron-hole recombination on pure $\mathrm{ZnO}$ NRs [hv $\rightarrow \mathrm{e}^{-}+\mathrm{h}^{+}$]. The electron of the pair stays in the conduction band, thereby raising conductivity and decreasing resistivity $\left[\mathrm{O}_{2}{ }^{-}\right.$(adsorption) $+\mathrm{h}^{+} \rightarrow \mathrm{O}_{2}$ (gas)]. By contrast, FZO NR arrays with high surface volume ratio can lead to their adsorption onto and desorption from the surface of FZO [41,42]. Therefore, their response speed and the carrier concentration in the FZO structure can be effectively improved; they can further contribute to the formation of more oxygen vacancies, thus enhancing the photocurrent of FZO PDs. $\mathrm{Zn}^{2+}$ ions in $\mathrm{ZnO}$ lattice are easily replaced by $\mathrm{Fe}^{3+}$ ions. However, the positive charge of substituted $\mathrm{Zn}^{2+}$ site (formation of electron-donor defects $\left[\mathrm{Fe}_{\mathrm{Zn}}\right]$ ) must be compensated by releasing electrons to keep its electrical neutrality. After Fe-doping, electrons are also introduced into the conduction band of the sample, which enhances the concentration of free electrons, resulting in the resistivity decrease of the FZO material, that is, the responsivity increases. The above description can be written as the following equation $[43,44]$ :

$$
\mathrm{Fe}_{2} \mathrm{O}_{3(\mathrm{~s})} \stackrel{\mathrm{ZnO}}{\longrightarrow} 2 \mathrm{Fe}_{\mathrm{Zn}}+3 \mathrm{O}_{\mathrm{o}}^{\mathrm{X}}+2 \mathrm{e}^{-}
$$

where in the Kroger-Vink notation, $\mathrm{Fe}_{\mathrm{Zn}}$ is an $\mathrm{Fe}$ ion sitting on a $\mathrm{Zn}$ lattice site with one positive charge, and $\mathrm{O}_{\mathrm{o}}^{\mathrm{X}}$ is an oxygen ion sitting on an $\mathrm{O}$ lattice site with a neutral charge. Based on the trapping mechanism related to oxygen adsorption/desorption, FZO NRs are remarkable materials for UV detection, as shown in Figure 8a.

The schematic energy band diagram of the Schottky barrier formed at the Ag/FZO interface in the dark and UV illumination is shown in Figure $8 \mathrm{~b}$. To the best of our knowledge, the presence of surface states at the semiconductor and metal interface can affect the Schottky barrier. In this investigation, interface surface states between FZO and $\mathrm{Ag}$, and oxygen adsorption and desorption effect can evidently change the height of the Schottky barrier. In a general dark environment, they form a high-energy barrier in the Schottky behavior $\left(\Phi_{\mathrm{B}}>\Phi_{\mathrm{B}^{\prime}}\right)$. Under UV irradiation, an electron-hole pair can be effectively produced, and carrier density can be substantially increased, which affects Fermi energy $[45,46]$. When UV light irradiates on the FZO PDs, it can produce numerous carriers, which can easily exceed the Schottky barrier, making the photocurrent and UV to-visible rejection ratio increase larger than that of pure ZnO PDs. Therefore, responsivities of FZO PDs are improved by the hole-trapping mechanism through oxygen adsorption and desorption in FZO NR arrays, which raises 
the density of trap states. In addition, this phenomenon can increase in carrier injection and transport, generating a consistent photocurrent. A comparison between the photosensitivity performance of the FZO NRs and these MOS structures previously reported is summarized in Table 2. As can be seen, the PD made of FZO NRs in the present work displays a higher photosensitivity than those reported in other studies, which confirms that FZO structures have a clear advantage over the others for UV sensing.

(a)

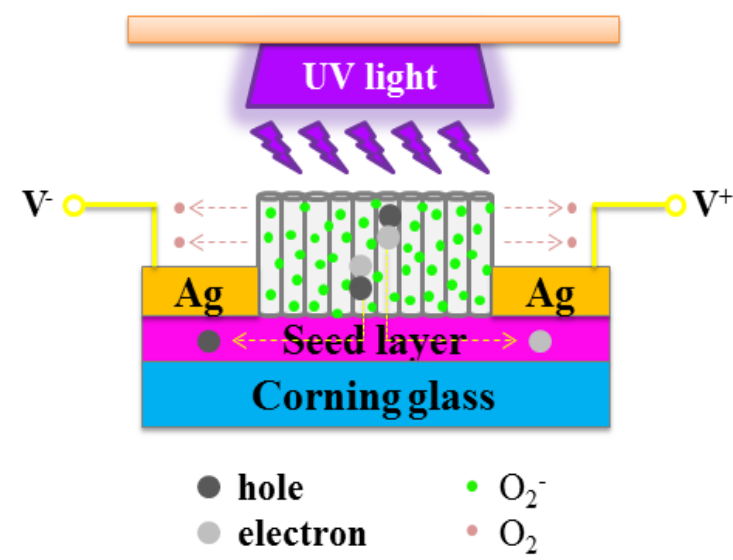

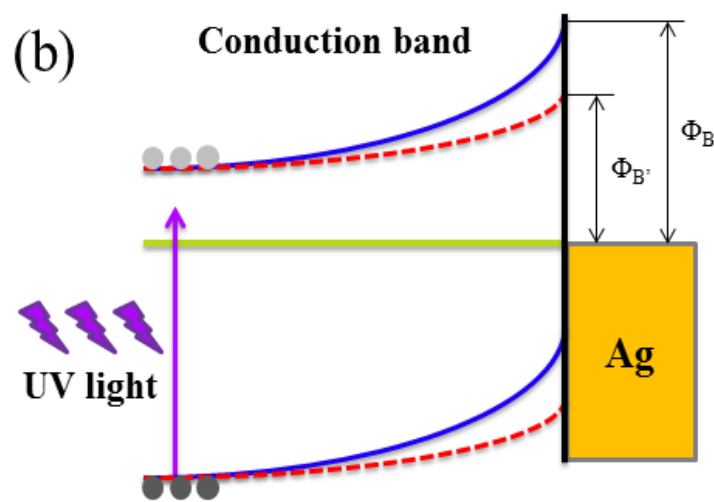

Valence band

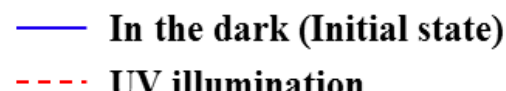

Figure 8. (a) Schematic diagram of FZO NR PDs under UV illumination. (b) The Schottky barrier formed at the interface between the FZO NRs and Ag electrodes, and the electron-hole pairs were photogenerated under UV light irradiation.

Table 2. Comparison of the photosensitivity characteristics of FZO NRs and other reported MOS structures.

\begin{tabular}{ccccccc}
\hline $\begin{array}{c}\text { MOS } \\
\text { Structures }\end{array}$ & $\begin{array}{c}\text { Bias } \\
(\mathbf{V})\end{array}$ & $\begin{array}{c}\text { Sensitivity } \\
\left(\mathbf{I}_{\mathbf{p h}} / \mathbf{I}_{\mathbf{d}}\right)\end{array}$ & $\begin{array}{c}\text { Rise Time } \\
\mathbf{( s )}\end{array}$ & $\begin{array}{c}\text { Decay Time } \\
\mathbf{( s )}\end{array}$ & $\begin{array}{c}\text { Responsivity } \\
(\mathbf{A} / \mathbf{W})\end{array}$ & Ref. \\
\hline Ni-ZnO NRs & 3 & 393.04 & 70 & 43 & 2.10 & {$[12]$} \\
Ga-ZnO NRs & 1 & 11.7 & 29.75 & 89.67 & $<0.05$ & {$[47]$} \\
Pure ZnO NRs & 1 & $<10$ & 42.9 & 132.9 & $\times$ & {$[48]$} \\
Fe-ZnO NRs & 1 & $\sim 49$ & 21.2 & 24.7 & 0.06 & {$[48]$} \\
$\mathbf{2}$ at\% Cd-ZnO film & 5 & 93.78 & 37.03 & 221.93 & $\times$ & {$[49]$} \\
$\mathbf{1 5}$ at\% Mg-ZnO film & 5 & 71.68 & 381 & 122.5 & $\times$ & {$[50]$} \\
FZO NRs & 3 & 471.1 & 46 & 37 & 0.758 & Present \\
\hline
\end{tabular}

\section{Conclusions}

In this paper, high single-crystalline FZO NR arrays were successfully synthesized on substrates by using a CBD method. Grown FZO NRs were used to fabricate high-performance UV PDs. FE-SEM and TEM images display the one-dimensional morphology of the FZO NR arrays with a hexagonal wurtzite structure. FZO NRs are structurally uniform and highly oriented preferentially in the c-axis direction with good crystal quality. XRD spectral analysis revealed that the (002) peak position was shifted to a higher angle by Fe-doping in the growth solution. $\mathrm{Fe}^{3+}$ ions substituted $\mathrm{Zn}^{2+}$ sites and entered into the $\mathrm{ZnO}$ lattice with no secondary phases or impurities of $\mathrm{Fe}_{2} \mathrm{O}_{3}$ and $\mathrm{Fe}_{3} \mathrm{O}_{4}$ exhibited in the grown samples. After Fe-doping, PL spectra of the samples revealed red-shifted in the presence of Fe in the ZnO structure. Compared with pure ZnO PDs, FZO NR PDs with $380 \mathrm{~nm}$ UV light at $3 \mathrm{~V}$ applied bias exhibited a high photocurrent with a sensitivity of 471.1 , which is attributed to the large number of electrons. Thus, the rise time and decay time of FZO PD samples are faster than 
those of pure ZnO PD samples. ZnO MSM PDs prepared with Fe treatment have potential for use in high-performance UV PDs and can be combined in Internet of Things sensor systems to detect high-radiation UV light exposure in the environment.

Author Contributions: Y.-L.C. performed the experiments; S.-J.Y. and L.-W.J. conceived the experiments; I.-T.T. and T.-T.C. participated in data analysis. All authors have read and agreed to the published version of the manuscript.

Funding: This research received no external funding.

Acknowledgments: This work was financially supported by the Ministry of Science and Technology of Taiwan under project numbers: MOST 107-2221-E-150-032, MOST 108-2221-E-024-006, MOST 108-2221-E-150-013-MY2, MOST 108-2622-E-150-010-CC3, and MOST 106-2221-E-150-041-MY3. The authors would like to thank the Common Laboratory for Micro/Nano Science and Technology of the National Formosa University for the use of their measurement equipment and their assistance in this work, the Center for Micro/Nano Science and Technology, National Cheng Kung University for device characterization, and C. H. Tsai for device fabrication and equipment support.

Conflicts of Interest: The authors declare no conflict of interest.

\section{References}

1. Amaro-Ortiz, A.; Yan, B.; D'Orazio, J.A. Ultraviolet Radiation, Aging and the Skin: Prevention of Damage by Topical cAMP Manipulation. Molecules 2014, 19, 6202-6219. [CrossRef] [PubMed]

2. D'Orazio, J.; Jarrett, S.; Amaro-Ortiz, A.; Scott, T. UV Radiation and the Skin. Int. J. Mol. Sci. 2013, 14, 12222-12248. [CrossRef] [PubMed]

3. Chu, T.T.; Jiang, H.L.; Ji, L.W.; Fang, T.H.; Shih, W.S.; Chang, T.L.; Meen, T.H.; Zhong, J.C. Characterization of UV photodetectors with $\mathrm{Mg}_{x} \mathrm{Zn}_{1-\mathrm{x}} \mathrm{O}$ thin films. Microelectron. Eng. 2010, 87, 1777-1780. [CrossRef]

4. Young, S.J.; Ji, L.W.; Chang, S.J.; Du, X.L. ZnO Metal-Semiconductor-Metal Ultraviolet Photodiodes with Au Contacts. J. Electrochem. Soc. 2017, 154, H26-H29. [CrossRef]

5. Aldalbahi, A.; Li, E.; Rivera, M.; Velazquez, R.; Altalhi, T.; Peng, X.Y.; Feng, P.X. A new approach for fabrications of SiC based photodetectors. Sci. Rep. 2016, 6, 23457. [CrossRef]

6. Liu, L.; Yang, C.; Patane, A.; Yu, Z.G.; Yan, F.G.; Wang, K.Y.; Lu, H.X.; Li, J.M.; Zhao, L.X. High-detectivity Ultraviolet Photodetectors based on Laterally Mesoporous GaN. Nanoscale 2017, 9, 8142-8148. [CrossRef]

7. Nayef, U.M.; Hubeatir, K.A.; Abdulkareem, Z.J. Ultraviolet photodetector based on $\mathrm{TiO}_{2}$ nanoparticles/porous silicon hetrojunction. Optik 2016, 127, 2806-2810. [CrossRef]

8. Chu, Y.L.; Ji, L.W.; Lu, H.Y.; Young, S.J.; Tang, I.T.; Chu, T.T.; Guo, J.S.; Tsai, Y.T. Fabrication and Characterization of UV Photodetectors with Cu-Doped ZnO Nanorod Arrays. J. Electrochem. Soc. 2020, 167, 027522. [CrossRef]

9. Huang, C.H.; Chu, Y.L.; Ji, L.W.; Tang, I.T.; Chu, T.T.; Chiou, B.J. Fabrication and characterization of homostructured photodiodes with Li-doped ZnO nanorods. Microsyst. Technol. 2020, 1. [CrossRef]

10. Espid, E.; Adeli, B.; Taghipour, F. Enhanced Gas Sensing Performance of Photo-Activated, Pt-Decorated, Single-Crystal ZnO Nanowires. J. Electrochem. Soc. 2019, 166, H3223-H3230. [CrossRef]

11. Young, S.J.; Wang, T.H. ZnO Nanorods Adsorbed with Photochemical Ag Nanoparticles for IOT and Field Electron Emission Application. J. Electrochem. Soc. 2018, 165, B3043-B3045. [CrossRef]

12. Chu, Y.L.; Ji, L.W.; Hsiao, Y.J.; Lu, H.Y.; Young, S.J.; Tang, I.T.; Chu, T.T.; Chen, X.J. Fabrication and Characterization of Ni-Doped ZnO Nanorod Arrays for UV Photodetector Application. J. Electrochem. Soc. 2020, 167, 067506. [CrossRef]

13. Lam, K.T.; Chu, Y.L.; Ji, L.W.; Hsiao, Y.J.; Chu, T.T.; Huang, B.W. Characterization of nanogenerators based on S-doped zinc oxide nanorod arrays. Microsyst. Technol. 2020. [CrossRef]

14. Young, S.J.; Tang, W.L. Wireless Zinc Oxide Based pH Sensor System. J. Electrochem. Soc. 2019, 166, B3047-B3050. [CrossRef]

15. Kim, W.; Chu, K.S. ZnO nanowire field-effect transistor as a UV photodetector, optimization for maximum sensitivity. Phys. Status Solidi A 2009, 206, 179-182. [CrossRef]

16. Shan, F.K.; Shin, B.C.; Jang, S.W.; Yu, Y.S. Substrate effects of ZnO thin films prepared by PLD technique. J. Eur. Ceram. Soc. 2004, 24, 1015-1018. [CrossRef]

17. Kim, J.B.; Byun, D.; Ie, S.Y.; Park, D.H.; Choi, W.K.; Choi, J.W.; Angadi, B. Cu-doped ZnO-based p-n hetero-junction light emitting diode. Semicond. Sci. Technol. 2008, 23, 095004. [CrossRef] 
18. Chikoidze, E.; Modreanu, M.; Sallet, V.; Gorochov, O.; Galtier, P. Electrical properties of chlorine-doped ZnO thin films grown by MOCVD. Phys. Status Solidi A 2008, 205, 1575-1579. [CrossRef]

19. Zhao, J.K.; Ge, S.S.; Pan, D.; Pan, Y.L.; Murugadoss, V.; Li, R.J.; Xie, W.; Lu, Y.; Wu, T.T.; Wujcik, E.K.; et al. Microwave Hydrothermal Synthesis of $\operatorname{In}_{2} \mathrm{O}_{3}-\mathrm{ZnO}$ Nanocomposites and Their Enhanced Photoelectrochemical Properties. J. Electrochem. Soc. 2019, 166, H3074-H3083. [CrossRef]

20. Kim, D.C.; Jung, B.O.; Kwon, Y.H.; Cho, H.K. Highly Sensible ZnO Nanowire Ultraviolet Photodetectors Based on Mechanical Schottky Contact. J. Electrochem. Soc. 2011, 159, K10-K14. [CrossRef]

21. Wang, R.C.; Hou, Y.R.; Liu, J.Y.; Chen, Y.W. Differentiating Ammonia from Other Reducing Gases via Response Reversal Phenomena by Varied $\mathrm{ZnO} / \mathrm{Cu}_{\mathrm{x}} \mathrm{O}$ Nanorod Arrays. J. Electrochem. Soc. 2018, 165, B484-B490. [CrossRef]

22. Young, S.J.; Yuan, K.W. Self-Powered ZnO Nanorod Ultraviolet Photodetector Integrated with Dye-Sensitised Solar Cell. J. Electrochem. Soc. 2019, 166, B1034-B1037. [CrossRef]

23. Anitha, R.; Ramesh, R.; Loganathan, R.; Vavilapalli, D.S.; Baskar, K.; Singh, S. Large area ultraviolet photodetector on surface modified Si:GaN layers. Appl. Surf. Sci. 2018, 435, 1057-1064.

24. Rambu, A.P.; Nica, V.; Dobromir, M. Influence of Fe-doping on the optical and electrical properties of ZnO films. Superlattice Microst. 2013, 59, 87-96. [CrossRef]

25. Zhang, W.H.; Zhang, W.D.; Zhou, J.F. Solvent thermal synthesis and gas-sensing properties of Fe-doped ZnO. J. Mater. Sci. 2010, 45, 209-215. [CrossRef]

26. Liu, C.W.; Chang, S.J.; Hsiao, C.H.; Liu, C.C.; Huang, R.J.; Lin, Y.S.; Su, M.C.; Wang, P.H.; Lo, K.Y. Diluted Magnetic Nanosemiconductor: Fe-Doped ZnO Vertically Aligned Nanorod Arrays Grown by Hydrothermal Synthesis. IEEE Trans. Nanotechnol. 2013, 12, 649-655. [CrossRef]

27. Sahai, A.; Kumar, Y.; Agarwal, V.; Olive-Mendez, S.F.; Goswami, N. Doping concentration driven morphological evolution of Fe doped ZnO nanostructures. J. Appl. Phys. 2014, 116, 164315. [CrossRef]

28. Yu, A.; Qian, J.S.; Pan, H.; Cui, Y.M.; Xu, M.G.; Tu, L.; Chai, Q.L.; Zhou, X.F. Micro-lotus constructed by Fe-doped ZnO hierarchically porous nanosheets: Preparation, characterization and gas sensing property. Sens. Actuat. B Chem. 2011, 158, 9-16. [CrossRef]

29. Chand, P.; Gaur, A.; Kumar, A.; Gaur, U.K. Structural, morphological and optical study of Li doped ZnO thin films on Si (100) substrate deposited by pulsed laser deposition. Ceram. Int. 2014, 40, 11915-11923. [CrossRef]

30. Chey, C.O.; Masood, A.; Riazanova, A.; Liu, X.; Rao, K.V.; Nur, O.; Willander, M. Synthesis of Fe-Doped ZnO Nanorods by Rapid Mixing Hydrothermal Method and Its Application for High Performance UV Photodetector. J. Nanomater. 2014, 2014, 524530. [CrossRef]

31. Dom, R.; Baby, L.R.; Kim, H.G.; Borse, P.H. Fe controlled charge-dynamics in ZnO for solar hydrogen generation. Int. J. Hydrog. Energy 2017, 42, 5758-5767. [CrossRef]

32. Wang, D.; Seo, H.W.; Tin, C.C.; Bozack, M.J.; Williams, J.R.; Park, M.; Sathitsuksanoh, N.; Cheng, A.J.; Tzeng, Y.H. Effects of postgrowth annealing treatment on the photoluminescence of zinc oxide nanorods. J. Appl. Phys. 2006, 99, 113509. [CrossRef]

33. Yang, Z.X.; Zhong, W.; Au, C.T.; Du, X.; Song, H.A.; Qi, X.S.; Ye, X.J.; Xu, M.H.; Du, Y.W. Novel Photoluminescence Properties of Magnetic Fe/ZnO Composites: Self-Assembled ZnO Nanospikes on Fe Nanoparticles Fabricated by Hydrothermal Method. J. Phys. Chem. C 2009, 113, 21269-21273. [CrossRef]

34. Saha, S.; Gupta, V. Al and Fe co-doped transparent conducting $\mathrm{ZnO}$ thin film for mediator-less biosensing application. AIP Adv. 2001, 1, 042112. [CrossRef]

35. Hassan, M.M.; Khan, W.; Azam, A.; Naqvi, A.H. Effect of size reduction on structural and optical properties of $\mathrm{ZnO}$ matrix due to successive doping of Fe ions. J. Lumin. 2014, 145, 160-166. [CrossRef]

36. Liu, Y.H.; Young, S.J.; Ji, L.W.; Chang, S.J. Noise Properties of Mg-Doped ZnO Nanorods Visible-Blind Photosensors. IEEE J. Sel. Topics Quantum Electron. 2015, 21, 3800405. [CrossRef]

37. Bera, A.; Basak, D. Carrier relaxation through two-electron process during photoconduction in highly UV sensitive quasi-one-dimensional ZnO nanowires. Appl. Phys. Lett. 2008, 93, 053102. [CrossRef]

38. Young, S.J.; Liu, Y.H. Ultraviolet Photodetectors With 2-D Indium-Doped ZnO Nanostructures. IEEE Trans. Electron Devices 2016, 63, 3160-3164. [CrossRef]

39. Wu, C.Z.; Ji, L.W.; Peng, S.M.; Chen, Y.L.; Young, S.J. MgZnO Nanorod Homojunction Photodetectors for Solar-Blind Detection. Electrochem. Solid-State Lett. 2011, 14, J55-J57. [CrossRef]

40. Heitz, R.; Hoffmann, A.; Broser, I. Fe ${ }^{3+}$ center in ZnO. Phys. Rev. B 1992, 45, 8997. [CrossRef] 
41. Ji, L.W.; Peng, S.M.; Su, Y.K.; Young, S.J.; Wu, C.Z.; Cheng, W.B. Ultraviolet photodetectors based on selectively grown ZnO nanorod arrays. Appl. Phys. Lett. 2009, 94, 203106. [CrossRef]

42. Peng, S.M.; Su, Y.K.; Ji, L.W.; Wu, C.Z.; Cheng, W.B.; Chao, W.C. ZnO Nanobridge Array UV Photodetectors. J. Phys. Chem. C 2010, 114, 3204-3208. [CrossRef]

43. Bai, S.L.; Guo, T.; Zhao, Y.B.; Sun, J.H.; Li, D.Q.; Chen, A.F.; Liu, C.C. Sensing performance and mechanism of Fe-doped ZnO microflowers. Sens. Actuat. B Chem. 2014, 195, 657-666. [CrossRef]

44. Guo, W.W. Design of Gas Sensor Based on Fe-Doped ZnO Nanosheet-Spheres for Low Concentration of Formaldehyde Detection. J. Electrochem. Soc. 2016, 163, B517-B525. [CrossRef]

45. Chen, T.P.; Young, S.J.; Chang, S.J.; Hsiao, C.H. Photoconductive Gain of Vertical ZnO Nanorods on Flexible Polyimide Substrate by Low-Temperature Process. IEEE Sens. J. 2011, 11, 3457-3461. [CrossRef]

46. Chen, T.P.; Young, S.J.; Chang, S.J.; Hsiao, C.H.; Huang, C.S. Field-Emission and Photoelectrical Characteristics of ZnO Nanorods Photodetectors Prepared on Flexible Substrate. J. Electrochem. Soc. 2012, 159, J153-J157. [CrossRef]

47. Hsiao, C.H.; Huang, C.S.; Young, S.J.; Chang, S.J.; Guo, J.J.; Liu, C.W.; Yang, T.Y. Field-Emission and Photoelectrical Characteristics of Ga-ZnO Nanorods Photodetector. IEEE Trans. Electron Dev. 2013, 60, 1905-1910. [CrossRef]

48. Chang, S.J.; Liu, C.W.; Hsiao, C.H.; Lo, K.Y.; Young, S.J.; Kao, T.H.; Tsai, K.S.; Wu, S.L. Noise Properties of Fe-ZnO Nanorod Ultraviolet Photodetectors. IEEE Photon. Technol. Lett. 2013, 25, 2089. [CrossRef]

49. Kumar, N.; Srivastava, A. Faster photoresponse, enhanced photosensitivity and photoluminescence in nanocrystalline ZnO films suitably doped by Cd. J. Alloys Compd. 2017, 706, 438-446. [CrossRef]

50. Kumar, N.; Srivastava, A. Green photoluminescence and photoconductivity from screen-printed Mg doped ZnO films. J. Alloys Compd. 2018, 735, 312-318. [CrossRef]

(C) 2020 by the authors. Licensee MDPI, Basel, Switzerland. This article is an open access article distributed under the terms and conditions of the Creative Commons Attribution (CC BY) license (http://creativecommons.org/licenses/by/4.0/). 